\title{
IDENTIFICATION OF TYPES OF BUFFALOES AVAILABLE IN KANIHARI BUFFALO POCKET OF MYMENSINGH DISTRICT
}

\author{
Md. Mahmodul Hasan Sohel ${ }^{1 *}$ and Md. Ruhul Amin ${ }^{2}$ \\ ${ }^{1}$ Department of Animal Science, Faculty of Agriculture, Erciyes University, Kayseri-38039, \\ Turkey; 'Department of Animal Breeding and Genetics, Faculty of Animal Husbandry, \\ Bangladesh Agricultural University, Mymensingh-2202, Bangladesh
}

*Corresponding author: Md. Mahmodul Hasan Sohel, E-mail: sohel.mmh@gmail.com

\section{ARTICLE INFO ABSTRACT}

\begin{abstract}
Received
22.03.2015

Accepted

12.04.2015

Online

19.04.2015

Key words

Buffalo Morphometric

Characterization

Kanihari

Buffalo-pocket

The buffaloes are reared by many races under diverse agro-climatic conditions of Bangladesh. The buffaloes of Bangladesh are mostly indigenous in origin. Both the swamp and river type buffaloes are found in Bangladesh and they can be found throughout the country. However, their concentration is higher in coastal part, Meghna-Ganga and Jamuna-Brahamaputra flood plain, subsequently forming buffalo pockets. This study was conducted to identify the types of buffaloes and the sources of breeding buffaloes in one of those buffalo pockets called Kanihari buffalo pocket situated in Mymenshing district. Direct interviewing method was used to collect the data from the owner of the buffaloes. According to the body shape, coat color and horn pattern, buffaloes of this region were categorized into different categories. Abundant natural green grasses in the river bank of old Brahammaputra gave this area as a shape of a buffalo pocket. This pocket does not have any distinct breed and the buffalo population is mostly mixed and exotic. Introduction of swamp germplasm occurred when buffalo cows are temporarily migrated to Bathan area of Sylhet. Morphometric characteristics (coat color, horn pattern and body appearance) of Type-1, Type-2 and Type-3 buffaloes are similar to Murrah group (Murrah and NiliRavi), Surti group and indigenous river type buffaloes, respectively. This is the first study which identifies and morphologically characterizes the buffalo population in Kanihari buffalo pocket; however, in depth genotypic study is required in order to identify the origin or breeds available in this area.
\end{abstract}

To cite this article: MMH Sohel and MR Amin. 2015. Identification of types of buffaloes available in Kanihari buffalo pocket of Mymensingh. Res. Agric. Livest. Fish. 2 (1): 109-115.

This is an open access article licensed under the terms of

RALF @ $14 / 2015$ the Creative Commons Attribution 4.0 International License

www.agroaid-bd.org/ralf, E-mail: editor.ralf@gmail.com 


\section{INTRUDUCTION}

The buffalo (Bubalus bubalis) population in the world is estimated at 185.28 million head which is spread over 42 countries, of which 179.75 million buffaloes (97\%) are found only in Asia (FAO, 2005). India has the largest buffalo population of 105.1 million and they comprise approximately $56.7 \%$ of the total world buffalo population. Bangladesh has around 830764 buffalo head owned by 270228 holdings representing $1.52 \%$ of the total holdings in the country (Faruque, 2003). During the last 10 years, the world buffalo population increased by approximately $1.49 \%$ annually. Worldwide interest has been developed on this species not only as a purveyor of animal protein in terms of meat and milk for human consumption, but also their adaptability to harsh environment. Furthermore, strong image linking between buffaloes with nature and environmentecological equilibrium, particularly in some of the world most marginal land shows this species as one of the most viable alternative of intensive cattle husbandry system (Hayashi et al., 2005).

Cattle and buffaloes are two important species supplying more than $99 \%$ of total milk consumed in Bangladesh. Bangladesh is a densely populated country where in each $\mathrm{km}^{2}$ approximately 964 people are living (BBS, 2011). To fulfill the growing demand of milk for a large population several attempts were made to mitigate the deficiency as well as to increase the total milk production of the country. However, most of the attempts were made to improve the genetic potential and production efficiency of cattle. These include small holding dairying, good management practice and introduction of crossbreeds to the domestic population. In addition with high yielding production potential crossbreed cows have several disadvantages including high quality feed requirement, susceptible to disease and low fertility. Therefore, it became necessary to choose alternatives for sustainable improvement of the consistent production. In this regard, buffalo can serve better than cattle. Moreover, buffaloes have a number of advantages over cattle. For instance, growing buffaloes may utilize coarse feed more efficiently than cattle (Singh and Mudgal, 1971), have more disease resistance ability and produce more solids in milk (Dubey et al., 1997) and require less management inputs. It has also been reported that buffalo holds strategic place in overall livestock economy of Bangladesh and serves three important purposes such as milk, meat and drought power supply (Ghaffar et al., 1991).

Dairy buffaloes are observed sparsely throughout the country. It has been reported that they are found to be concentrated in Meghna-Ganga flood plain as well as Brahammaputra-Jamuna flood plain (Faruque et al., 2007b). In addition, there are few buffalo pockets in Bangladesh including Coastal area, Sylhet haor area, Sugar cane belt of Jamalpur and Kanihari buffalo pocket in Trishal upazila of Mymenshing district. Among all the buffalo pockets particularly Kanihari buffalo pocket draw our attention because it has been reported that the people of Kanihari area used to keep buffaloes beside cattle mainly for milk production over hundreds of years and the genetic and phenotypic evaluation of these buffalo population has not been done yet. Higher concentration of dairy buffaloes in this area may be due to higher abundance of green grasses, milk marketing opportunity and higher price of buffalo milk than cow milk. However, this pocket does not have any particular breed and the owners do not follow any specific breeding plan. During the breeding season breeder buffaloes with different genetic makeup are reported to come from India through various rout. Moreover, introduction of swamp germplasm to the population has higher chance during the time when buffaloes are temporarily migrated to Sylhet bathan area (Faruque 2007a).

Therefore, aimless breeding of these animals were taking place causing no visible genetic improvement rather a gradual decrease in production can be noticed. Neither government nor NGOs were found to be involved in this area to improve the current condition of these animals in the pocket. Farmers of this area are often confused to choose the correct breed or type of buffaloes for breeding purpose which can serve them properly. Under these circumstances, a thorough study on the resource and potential of the pocket is appeared to be very essential in order to have a clear scenario of the genetic resources and production potential of the milk buffaloes. Considering these facts, current study was conducted i) to identify the routes of breeder buffaloes/seeds in the pocket and ii) to determine the breeds or types of buffaloes available in this area by morphometric characterization. 


\section{MATERIAL AND METHODS}

The current experiment was conducted to identify the types of buffaloes on the basis of their phenotypic appearance. Data was collected within a period of 12 months starting from May 2007 to April 2008. In order to collect data a door to door survey was carried out. To know the origin of a particular buffalo, information was collected from its owner using a standard questionnaire.

\section{Location of the study area}

Kanihari union at Trishal upazila was selected for the present study. The influencing factors in choosing Kanihari union as study area were- localized concentration of buffaloes gave a form of buffalo pocket in this area, no substantial study was conducted previously in this area and it was well communicated which might be helpful for the researcher in collecting the data required for the research. First the study area was segmented into three parts namely Area 1, Area 2 and Area 3 in order to ease collection of data. Area 1 consists of village Jilki, Gobindapur, Balidia and Betra whereas Area 2 consists of village Kuista, Baghadaria and Garpara. On the other hand Area 3 consists of village Thapanhala, Dewpara and Sultanpur.

\section{Number of animals}

Animals were randomly selected from the whole study area. Data from 120 animals, of which 45 from Area 1, 40 from Area 2 and 35 from Area 3 were collected using a suitable questionnaire.

\section{The survey schedule}

The questionnaire was prepared in accordance with the objectives of our study. It was designed in a simple manner to obtain accurate and as much as information possible from the farmers. The questionnaire comprised of following major items-

a) General information about the selected livestock owner i.e. occupation, income, income from livestock and family size etc.

b) Purchase and breeding history of the buffalo

c) Live weight

d) Phenotypic and morphologic assessments i.e. coat color, horn pattern etc.

\section{Data collection, record keeping and statistical analysis}

Door to door interviewing method was used to collect the data from specific buffalo owners. Information given by the owner was recorded in a record book and kept for further analysis. After collection, data were processed, tabulated and analyzed using Statistical Program for Social Science (SPSS, Version 16.0) computer program.

\section{RESULTS AND DISCUSSION}

\section{A glimpse on Kanihari Buffalo pocket}

Kanihari Union (terminal local govt. unit) is located $25 \mathrm{~km}$ south from Mymensingh city and $100 \mathrm{~km}$ north from capital Dhaka along west side of old Brahamaputra river. The extended sandy and loamy basin of old Brahamaputra River provided this area as an excellent grazing land particularly in wet season. The union consists of 12 villages, among them Jhilki, Sultanpur, Kuista and Chor-baghadaria possesses highest number of buffaloes. There are around 285 household rearing approximately 850 buffalo heads. It is reported that from hundred years back people of this area used to keep buffaloes beside cattle mainly for milk production. Higher concentration of dairy buffaloes in this area might be due to firstly, abundance of natural grasses which grow over the sandy and loamy basin of old Brahammaputra river and buffalo can utilize these grasses better than cattle. Secondly, high demand and milk marketing opportunity in Mymensingh Sadar mainly for raw consumption and production of milk products. Milk traders used both rail and water route to bring the milk from Kanihari to Mymensingh city. Thirdly, because of buffalo milk contain higher total solid and fat, typically buffalo milk sells at almost double price than cow milk. It is a general observation that buffaloes in Kanihari produced 
3-5 times higher amount of milk each day than cattle. While daily milk production of cattle is 1-2 lit, buffalo produce 5-8 lit milk/day. Furthermore, the price of buffalo milk is higher than cow milk because it contain higher amount of total solids and fats. It is important to note that farmers who rear buffaloes side by side of their main occupation, they are generating 35-40\% more of their total income. Because of these facts buffaloes are popular in Kanihari and it became an integral component of livestock agriculture in this area.

\section{Sources of buffalo stock and breeding policy}

Replacement and introduction of exotic buffaloes can occur in several ways. We observed that there are at least four main sources from where buffaloes are get into this area-
a) Locally born replacement calves
b) Indian buffaloes coming through traders via different routes
c) Buffaloes from Sylhet Bathan area
d) Buffaloes from Myanmar (Barma), reported by some farmers

Farmers used to buy buffaloes in different recognized market such as Gabtoli Market, Kalimela in Dinajpur district. Some farmers buy and sell their buffaloes when they are migrated temporarily in the Bathan are of Sylhet. Sometime traders bring their buffaloes directly in Kanihari and sell to farmers.

We found that Kanihari buffalo pocket does not have any distinct breed and the buffalo population is mostly mixed. It is alarming to note that the owners are not following any specific breeding plan. As a result aimless and haphazard breeding of buffaloes were taking place in this area. They are typically inseminated by locally available bulls or by swamp buffaloes when they are temporarily migrated to bathan area causing introduction of swamp germplasm in this area. Therefore, there is a gradual decrease in milk production performance was observed in locally born replacement crossbreeds (River $\times$ Swamp) or (Exotic $\times$ Deshi).

\section{An overview of Types of buffaloes observed in Kanihari Buffalo Pocket}

We collected data from 120 owners which are corresponding 120 adult buffaloes. Among the buffaloes investigated there are at least four types of buffaloes were found to be identified in this area and subsequently, they were grouped as Type-1, Type-2 and Type-3. Each type of buffaloes has distinct coat color, special markings, specific horn pattern and different production potential. An overview of different types buffaloes are listed in Table 1. Phenotypic characterization generally refers to the process of identifying distinct breed populations and describing their external and production characteristics within a given production environment. The term "production environment" is here not only refer the natural environment but also include the management practices and as well as social and economic factors. It is well known that each breed has distinct characteristics and it is possible to assess the type or breed of buffalo by analyzing its phenotypic characteristics. Keeping these facts in mind, in order to have a clear idea about the buffalo population in Kanihari Buffalo Pocket different phenotypic aspect were analyzed including body appearance, coat color and horn pattern.

Table 1. Morphological characterization buffaloes in Kanihari buffalo pocket

\begin{tabular}{|llllll|}
\hline Group & Local name & Coat color & Horn pattern & $\begin{array}{l}\text { \% of total } \\
\text { population }\end{array}$ & $\begin{array}{l}\text { Farmer's } \\
\text { preference }\end{array}$ \\
\hline Type-1 & Gurjuti & $\begin{array}{l}\text { Jet black, soft, } \\
\text { smooth \& scanty } \\
\text { hair }\end{array}$ & $\begin{array}{l}\text { Short, tightly curled \& } \\
\text { forming coil }\end{array}$ & 20.14 & 35 \\
Type-2 & Nepali & $\begin{array}{l}\text { Fawn or black, } \\
\text { rusty brown hair } \\
\text { and black or white } \\
\text { switch } \\
\text { Black }\end{array}$ & $\begin{array}{l}\text { Short to medium in size } \\
\text { and sickle shaped }\end{array}$ & 43.24 & 45 \\
Type-3 & $\begin{array}{l}\text { Deshi } \\
\text { (milk type) }\end{array}$ & $\begin{array}{l}\text { Comparatively large, no } \\
\text { definite shape }\end{array}$ & 36.62 & 20 \\
\hline
\end{tabular}


Body appearance: Type-1 buffaloes have sound build, massive and heavy barreled shaped body with comparatively short head but long face and neck and udder is well developed. They have long tail which in generally reaching to the fetlock joint. Similar type of body structure and appearance was observed in Murrah breeds (Sangwan, 2012). On the other hand Type-2 buffaloes are medium in size, well-shaped body with a wide and long head and the udder is well developed and extends well forward up to the naval flaps. These body characteristics are typical for Surti breeds (Sangwan, 2012). Type-3 buffaloes are comparatively smaller in size than Type-1 and Type-2 buffaloes. And they have wide forehead with a long face. The udder is smaller in size with longer teat compare to Type-1 and -2 .

Coat color: Each breed has distinct coat color and hair pattern. It has been observed that the coat color of the buffaloes in this area was found to be ranged from fawn/light black to jet black. The coat color of Type-1 buffalo is predominantly jet black with soft, smooth and scanty hair. Coat color of Type-2 buffaloes was ranged from black, rusty brown to reddish. Among the Type-2 buffaloes, we found around $60 \%$ animals have rusty brown coat color and $40 \%$ animals have black coat color in this area. On the other hand, Type-3 buffaloes have black coat color. Interestingly, one albino buffalo calf was found in Kanihari buffalo pocket, however, its genetic background was unknown. It has been reported that, wide range of skin and coat color can be observed among the various breeds and types of water buffaloes throughout the world. Coat color varies with the age, husbandry practice and in relation to the degree of exposure to the solar radiation. The coat color of most breed darkens gradually with the advancing of age, especially after the first five years of life (Macgregor, 1941). Pundir and his colleagues mentioned that Surti buffaloes are usually copper colored with scanty hair which is black at the roots and reddish brown at the tips and some time the hair is completely rusty brown (Pundir et al., 2000). It has been reported by Faruque (1989) that the coat color of buffaloes in Bangladesh is jet black in western region, deep grey to light grey in central and eastern region. The coat color of buffaloes in south east region is predominantly grey (Faruque and Amin, 1994).

Special markings: Chevron marking on the chest was found in $17.39 \%$ of the buffaloes in Kanihai. In general, typical Surti buffalo has two strips or chevrons on its chest. White spot in forehead was found in $12.55 \%$ of buffaloes, while white tail switch was observed in $62.15 \%$ of the buffaloes. White spots on forehead and tail-switch are characteristics markings for Surti breed. It has been reported by Faruque (2003), a typical Bangladeshi indigenous buffalo is river type and sometime white tail-switch can be observed. However, white markings on forehead and tail switch can be seen also in Murrah breeds but it is not preferred. Nili-Ravi buffaloes are similar to Murrah in almost all characteristics except the white markings on extremities. They have usually wall eyed and have white markings on forehead, face and tip of the tail (Banerjee, 2011).

Horn pattern: Buffaloes in Kanihari have a wide range horn pattern starting from short curled to long shaped horns. For example, Type-1 buffaloes possess short, tightly and spirally curved horns. This type of horn pattern has been reported for the characteristic phenotype of Murrah buffalo breed (Rife, 1962). Type-2 buffaloes have flat horns with medium to short in length, sickle shaped and are directed downward and backward, and then turn upward. Although, Type-3 buffaloes have no definite horn shape; however, they possess comparatively large horns which are generally grow backward then upward and then forward forming hook-shaped structure. Many river buffaloes have spirally curled horns. They are tightly coiled in Murrah, NiliRavi and Kundi, downward curving in the Jafrabadi (Freed et al., 1981). The horns of Murrah buffaloes are different from other breeds, in general they are short, tight, turning backward and then upward and finally curving spirally inward. The horns get loosened slightly but spiral curves increased with the advances in age (Cruz-Cruz et al., 2014). The horns of Surti buffaloes are of medium length and sickle-shaped with flat and transverse corrugations. They are directed downward and backward and then turn upward at the tip to form a hook (Banerjee, 2011). Crosses between Murrah and Swamp produce medium sized slightly curled horns (Mingala et al., 2007). The horns of the buffaloes in the Southeast coastal areas of Bangladesh are of crescentic shape. This pattern of the horns is also found in most buffaloes in the south and some buffaloes in the south west. Small, spiral curled pattern horns are found in some cases in the south and south west coastal region (Faruque, 1994). In Brahammaputra-Jamuna flood fed area the horns of dairy buffaloes resemble to those of river type; curly horns through in few cases hanging horns were also observed (Fahimuddin, 1975; Mahadeven 1992). In Meghna Ganges flood plain areas most of the dairy buffaloes had crescentic horn which 
is the characteristics of swamp buffalo (Fahimuddin, 1975). The horn pattern of buffaloes in Tangail district ranged from spiral to almost crescentic (Hussen, 1990).

Cockrill described the buffaloes of Bangladesh as non-descriptive types. No substantial attempts were made to identify and characterized native buffalo stocks before 1980 . After that attempts were made by Faruque (1990); Faruque and Amin (1995) to characterize the native and exotic buffalo population in different region of Bangladesh. Faruque (1994) reported that the coat color of buffaloes in Mymensing region varied from jet black to light grey. They also mentioned some buffaloes are with white stockings, tail switch and spot in forehead without mentioning their frequency. The results of this study provide a clear picture of different types of buffaloes in Kanihari buffalo pocket by analyzing their morphologic characteristics.

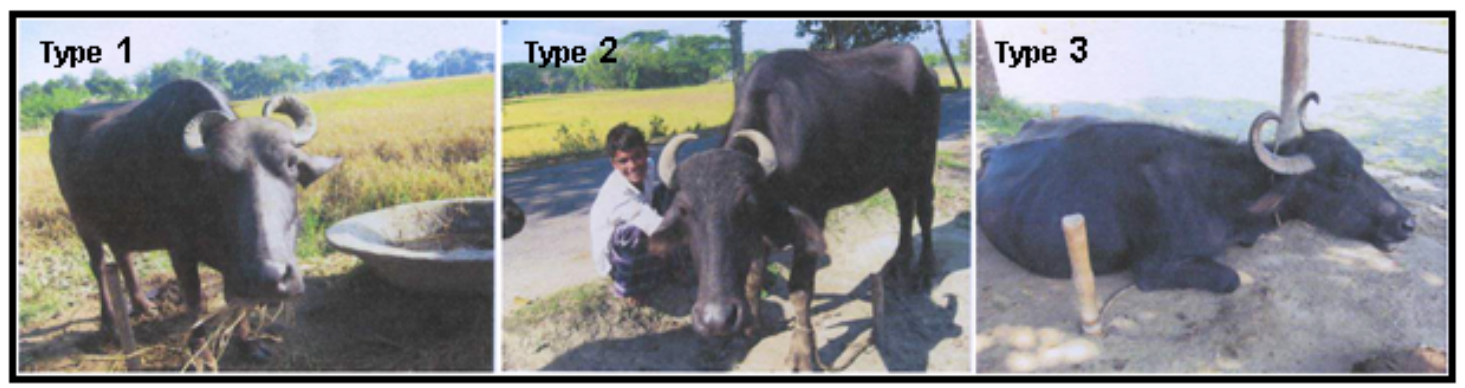

Figure 1. Horn pattern of three types of buffaloes available in Kanihari buffalo pocket

\section{CONCLUSION}

Our study suggests that the buffaloes in this region are an integrated part of livestock agriculture which has a strong impact on socio-economic condition of owners. Moreover, it can be concluded from the observed results and discussion that the morphometric characteristics of Type-1, Type- 2 and Type-3 buffaloes are similar to Murrah group (Murrah and Nili-Ravi), Surti group and indigenous river type buffaloes, respectively. We also found few buffaloes with the characteristics of indigenous swamp buffalo in this region, however their frequency is very low (total of 5 in the study area) and they are mainly used for drought purpose. In addition to this study, we strongly suggest in depth studies in genetic level in order to identify the genetic origin of these buffaloes in study region.

\section{ACKNOWLEDGEMENT}

The authors would like to thank Prof. Dr. Shamsuddin and his team for their help during this study. The authors would also like to thank Masreka Khan for her contribution during preparation and editing the manuscript.

\section{REFERENCE}

1. Banerjee GC, 2011. A Textbook of Animal Husbandary, 8th ed., p. 703. Published by Oxford \& IBH Publishing Co. Pvt. Ltd., New Delhi, India.

2. BBS, 2011. $5^{\text {th }}$ National Census. http://www.bbs.gov.bd/home.aspx.

3. Dubey PC, CL Suman, MK Sanyal, HS Pandey, MM Saxena and PL Yadav, 1997. Factors affecting composition of buffalo milk. Indian Journal of Animal Science, 67: 802.

4. Fahimuddin M, 1975. Domestic water buffalo, Oxford \& IBH Publishing, New Delhi, India.

5. FAO, 2005. Buffalo production and research. ftp://ftp.fao.org/docrep/fao/010/ah847e/ah847e.pdf.

6. Faruque MO and MI Hossain, 2007b. The Effect of Feed Supplement on the Yield and Composition of Buffalo Milk. Italian Journal of Animal Science, 6: 488-490. 
7. Faruque MO and MR Amin, 1995. Indigenous buffaloes in the coastal area of Bangladesh. Part II. Productivity of indigenous buffaloes in the south western coastal area. Bangladesh Journal of Training and Development, 8: 138-140.

8. Faruque MO, 1994. The indigenous buffalo in the Mymensingh district of Bangladesh. Buffalo Journal, 2: 91-100.

9. Faruque $\mathrm{MO}, 2003$. Buffalo production system in Bangladesh. Proc. of the Fourth Asian Buffalo Congress, New Delhi, India, 25 to 28 Feb.: 31-35.

10. Faruque MO, 2007a. The Genetic diversity of Bangladeshi Buffaloes. Italian Journal of Animal Science, 6: 349-352.

11. Faruquel MO, MA Hasnath and NU Siddique, 1990. Present status of buffaloes and their productivity in Bangladesh. Asian Australian Journal of Animal Science, 3 (4): 287-292.

12. Freed SA and RS Freed, 1981. Sacred Cows and Water Buffalo in India: The Uses of Ethnography. Current Anthropology, 22: 483-502.

13. Ghaffar A, MI khan, MA Mirza and WH Prizada, 1991. Effect of year and calving season on some traits of economic importance in Nili-Ravi buffaloes. Pakistan Journal of Agricultural Research, 12: 217.

14. Hayashi Y, KL Maharjan and H Kumagai, 2005. Feeding Traits, Nutritional Status and Milk Production of Dairy Cattle and Buffalo in Small-scale Farms in Terai, Nepal. Asian-Australasian Journal of Animal Science, 19: 189-197.

15. LA de la Cruz-Cruz, I Guerrero-Legarreta, R Ramirez-Necoechea, P Roldan-Santiago, P MoraMedina, R Hernandez-Gonzalez and D Mota-Rojas, 2014. The behaviour and productivity of water buffalo in different breeding systems: a review. Veterinary Medicine, 59: 181-193.

16. Mahadevan P, 1992. Distribution, ecology and adaptation of river buffaloes. In: Buffaloproduction, production-system approach. (Eds. M. H. Tulooh, J.H.G. Holmes World Animal Science, c6), Elsevier Scientific Publications, Amsterdam, Netherlands. p. 1-58.

17. Mcgregor R, 1941. The domestic buffalo. Veterinary Research, 53: 443-450

18. Mingala CN, R Odbileg, S Konnai, K Ohashi and M Onuma, 2007. Molecular cloning, sequencing and phylogenetic analysis of inflammatory cytokines of swamp type buffalo contrasting with other bubaline breeds. Comparative Immunology, Microbiology and Infectious Diseases, 30: 119-31.

19. Prasad RMV, K Sudhakar, ER Rao, BR Gupta and M Mahender, 2010. Studies on the udder and teat morphology and their relationship with milk yield in Murrah buffaloes. Livestock Research for Rural Development, 22: 20.

20. Pundir RK, G Sahana1, NK Navani, PK Jain1, DV Singh, Satish Kumar and AS Dave, 2000. Characterization of Mehsana Buffaloes in India. Animal Genetic Resources Information, 28: 53-62.

21. Rife DC, 1962. Color and horn variations in water buffalo. The inheritance of coat color, eye color and shape of horns. Journal of Heredity, 53: 239-46.

22. Sangwan ML, 2012. Analysis of Genetic Diversity of Indian Buffalo Breeds by DNA Markers. Journal of Buffalo Science, 1: 91-101.

23. Singh, BB and BP Singh, 1971. Comparative study of life-time economics of Haryana cows versus Murrah buffaloes. Indian Veterinary Journal, 48: 485-489. 